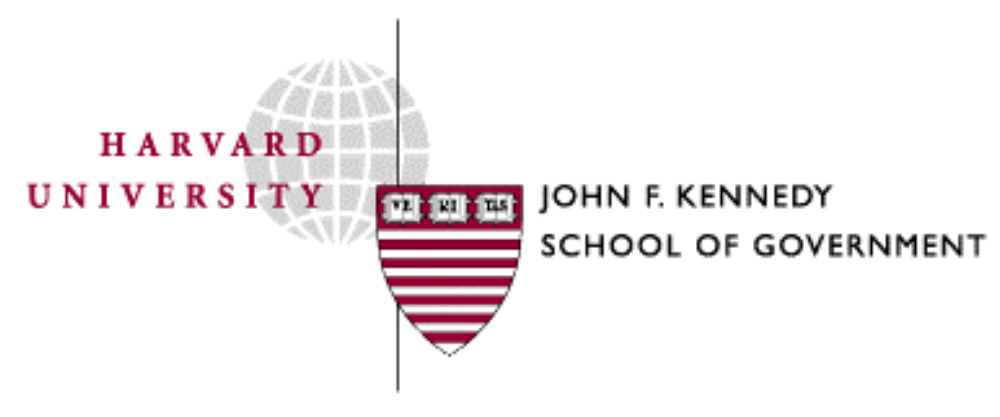

Faculty Research Working Papers Series

\title{
Changing Big Government Organizations: Easier than meets the eye?
}

\author{
Steven J. Kelman
}

\author{
May 2004 \\ RWP04-026
}

The views expressed in the KSG Faculty Research Working Paper Series are those of the author(s) and do not necessarily reflect those of the John F. Kennedy School of Government or Harvard University. Copyright belongs to the author(s). Papers may be downloaded for personal use only. 


\section{Changing Big Government Organizations: Easier than meets the eye?}

by

Dr. Steven Kelman

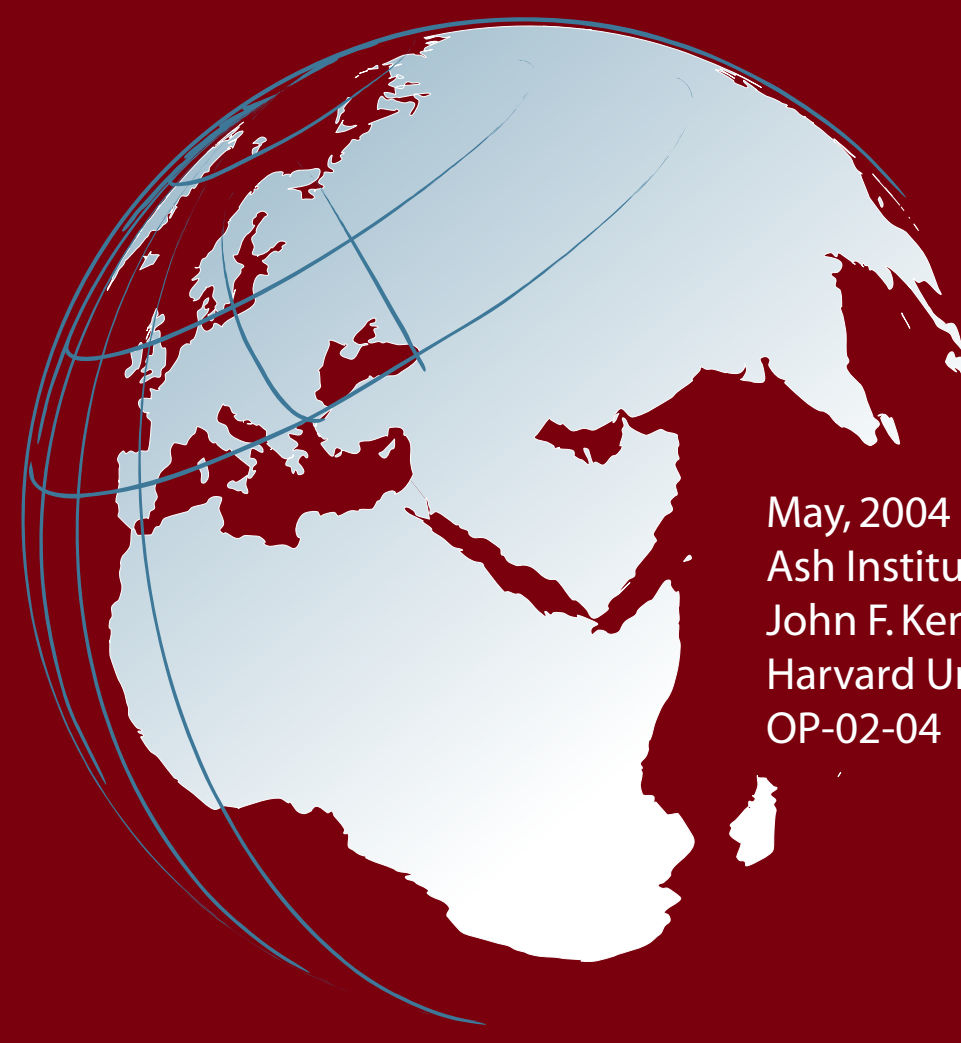


The need for government organizations to change how they work is a major theme among practitioners and observers of government, discussed informally and repeated constantly at conferences for practitioners. The need for organizational change is also a preoccupying theme in the business world. But the impetus for change in government is somewhat different. In the private sector, the assumption is that the organization's current performance is good, but that shifts in the organization's environment demands changes in what the organization produces or how it produces it. In government, by contrast, the impetus for organizational change is typically that current performance isn't what it should be. Government isn't working as well as it should, and organizational change is needed to improve performance.

However, changing government organizations, if one listens to speakers at conferences where the topic is discussed, is seen as excruciatingly difficult. Phrases such as "obstacles," "barriers," and "resistance to change" dominate. It is frequently argued that only crisis (often called a "burning platform”), or leaders relentlessly pushing change down the throats of reluctant people within the organization, can provoke change.

I was engaged in an effort, in the context of the Clinton Administration's "reinventing government” program, to achieve organizational change in the government's procurement system - reform of how the federal government buys $\$ 200$ billion a year of products and services, over $30 \%$ of discretionary spending. (I did so while on leave from teaching public management at the Kennedy School of Government at Harvard University to serve as Administrator of the Office of Federal Procurement Policy, the federal government's senior procurement policy official, a Senate-confirmed presidential appointment.) I worked closely with another political appointee, Colleen Preston, Deputy Assistant Secretary of Defense for Acquisition Reform. Observers more objective than I - such as the authors of a Brookings Institution report on management reform in the Clinton administration - agree that the effort did succeed in instituting significant change in how the government's procurement organizations behaved.

The specific kind of change occurring was debureaucratization. Previously, procurement offices had corresponded to a stereotype of government bureaucracy. They were rulebound, slow, and 
not results-driven. After the changes, they became speedier and more nimble. They began to pay more attention to quality in choosing suppliers, which required them to exercise judgment more. Given an opportunity to use discretion, many developed novel ways to structure contracts. (Since the 1990s, procurement reform has been threatened by political winds external to the procurement system. In particular, fallout from opposition to American policy in Iraq, which created increased worries about favoritism in contract awards-with particularly scrutiny of contracts awarded to Halliburton, where Vice President Cheney had been CEO_and increased demands for oversight of contractors, has increased the demand for more rules and oversight to prevent "abuse." However, to the extent these pressures have appeared, they have not come from rejection of reform on the part of frontline employees within the system itself, among whom the changes had in significant measure taken root.)

As of the time procurement reform began, most observers would have thought that gaining the support of frontline procurement employees for changing the traditional bureaucratic emphasis of the procurement system would have been particularly difficult. The reason was that, though the system was unpopular with users who needed to buy products or services, knowledge of the regulations and control over compliance with them was the major source of the status of those working in procurement offices. One could easily imagine a situation where top political leaders announced changes in how the system should operate, but nothing ended up happening on the ground.

After returning to academia, I gathered information from frontline employees and first-line supervisors in 19 buying offices, after the change effort had gone on for five years, to learn more about the spread of reform to the front lines of procurement organizations. Five of these offices were in the Army, four the Air Force, two the Defense Logistics Agency (which buys commercial items such as food and pharmaceuticals), and the rest in five civilian cabinet departments, including four that were units of a single department. Data were gathered using a survey for all frontline employees in these offices, administered on-the-job on my behalf by each office, with responses from 1593 civil servants. The survey included over 400 fixed-format attitudinal, demographic, and other questions. Together with a research assistant, I also conducted 272 interviews, using a structured questionnaire with mostly open-ended questions, 
with people working at various levels of these offices, including upper-level supervisors and the heads of each office.

Procurement reform was successfully initiated without the system having experienced any "burning platform.” Furthermore, the research shows that crises befalling the procurement system after the change effort began (workforce downsizing and elimination of the monopoly status of some organizations as providers of procurement services) actually hurt progress of the change, rather than helping it. Instead, the research suggests that successfully changing large organizations may be less difficult than is ordinarily thought. Put another way, more possibilities for successful change in large government organizations exist than many realize.

The research examines both how reform gained a foothold on the front lines of the system when governmentwide leaders first initiated the change effort and also how support for reform eventually achieved majority status among frontline employees.

- Gaining a foothold for reform was less difficult than many would have supposed because, while a majority of people on the front lines of the system were initially skeptical of or opposed to the change effort, there was a significant minority of supporters who moved into action when top leaders announced the change.

- $\quad$ Moving to majority status was possible both because many people had good experiences with the change once they tried it, and also-importantly-because, as the change effort persisted (i.e. was not abandoned by the change leaders after a while for some new priority project), forces got set in motion that increased support for the change due to the mere passage of time, independent of people's actual personal experience with the change.

The arguments for why change is difficult are not so much wrong as they are incomplete. All the reasons why people often become attached to ways they've done business in the past, cited by those convinced that changing government organizations is extraordinarily different, are correct. But the "people resist change” view ignores the fact that most social arrangements are likely to create discontent as well as satisfaction. Those discontented with established arrangements form a constituency for change. 
In the case of the traditional procurement system, one major such source of dissatisfaction was unhappiness over the lack of job autonomy that the heavy overlay of rules and hierarchy (signoffs and reviews) produced. Second, the increased bureaucracy growing out of the system's growing volume of regulations and signoffs caused increased job burdens and stresses. In addition to these sources of discontent, there were other sources of dissatisfaction with the traditional system. The spread of total quality management, and the "customer" concept associated with it, heightened concerns about tensions between procurement people and endusers on whose behalf procurement people were buying. And, some challenged the preoccupation of the traditional system with process over results, favoring a new ideology centered on gaining better value for the government. A significant proportion of frontline employees felt one or more of these sources of dissatisfaction, though of course not all those feeling such dissatisfaction would have classified themselves as critics of the existing system (since they may also have felt countervailing reasons to support the status quo).

Thus, the traditional system, as of the time procurement reform was launched, was controversial. It had supporters. But it also had critics. People disagreed. This is different from most thinking about the difficulties of organizational change, where "people" in general are assumed to oppose change.

Some frontline employees consciously saw themselves as advocates of a debureaucratized system. Although few were doing much to put their thoughts into action, they were, so to speak, procurement reformers before procurement reform. I call this group the "change vanguard,” and I estimate from my data that perhaps as many as $18 \%$ of frontline employees were members. In addition, when reform got launched, the change vanguard was joined by a second group who, although they had not previously conceptualized themselves as advocates of reform, became favorably disposed to giving reform a try early after it got started. I call this group "early recruits.” Together these two groups constituted a "change coalition.” Even together, the change coalition didn’t constitute a majority - I estimate at most about $40 \%$ of frontline employees were in the change coalition. 
Thus, rather than embracing the generalization "people resist change," it is more appropriate to see the top-level initiation of an organizational change effort as setting in motion a political struggle, and to see organizational change on the front lines of government as a political process.

The proclamation of procurement reform by leaders at the top, an action undertaken independently of the development of discontent at the working level (and hence a sort of exogenous shock to the political decision-making process in local offices), provided the change vanguard already present at the local level with the opportunity to initiate reform in their organizations, something they had wanted to do even before reform was announced, and making them stronger politically within their buying offices. Thus, procurement reform was able to gain a foothold on the front lines of the system.

Most of those in the change vanguard would not move without a signal from the top because they would have felt that their chances for success were small. The most obvious reason for this was they were far from a majority in their offices. Beyond that, in large, hierarchical government (and most private) organizations, it is not considered legitimate for people at the working levels to initiate on their own major changes in how the organization does business without authorization from "headquarters." Most career government employees share the norm that they should not act contrary to policies their organization's senior political leadership establishes. Even if a person on the front lines didn't share the norm of deference to political leadership, he or she would likely have perceived that efforts to institute changes top leaders didn’t desire would have created a significant risk of punishment. Finally, the change vanguard was discouraged from moving without a signal from the top because there were significant limits to what they would be able to accomplish, even in theory, at the local level, without legal or regulatory changes. Important alterations the change vanguard might have wanted would have not just been violations of norms about deference to political leaders, but outright illegal actions.

Through their actions, top leaders in effect intervened in the politics of local buying offices. People who, absent a signal from above, mostly would have just nurtured their opinions and went about their jobs in the old way rose up. The announcement of reform provided an opportunity by authorizing, energizing, and strengthening the hand of the change vanguard. 
Top leaders authorized members of the change vanguard to "come out." More than that, the support of top leaders for reform made it more difficult for local critics openly to criticize the change vanguard's moves to proceed, because now critics were in the same position as those in the change vanguard had been prior to reform: they lacked authorization to criticize. Authorization from the top also eased people's minds about the consequences of possible failure. This applied not just to the change vanguard, but to people trying to decide whether to become early recruits of reform. If top leaders were urging changes be tried, the negative consequences of failure were lower than if changes had been undertaken at a person's own personal initiative.

The most important way top leaders strengthened the hand of the change vanguard was through their contribution to providing the change vanguard additional supporters - the early recruits - to get added to the mere one in five (or fewer) they initially had. They provided an infusion of "votes" to influence the outcome of local political processes determining how the office would react to the reform effort. Also importantly, the intervention of top leaders strengthened the hand of the change vanguard by offering them an additional, and powerful, argument to use with fencesitters or even critics/skeptics about why they should participate in change, or at least not resist it. It allowed them to use arguments such as, "We are being told to do this; we have no choice,” “Our leaders want us to change,” or “There’s lots of pressure on us to change,” suggesting that the local advocate was acting simply as a bearer of demands from the outside. Referring to the necessity of bowing to outside pressure is an appealing approach for a change advocate to take. It removes, or at least reduces, interpersonal contention between supporters and opponents over the substantive question of whether the new policies are a good idea, with all the psychological identification with one’s views and the power implications of changing one’s mind that occurs when the debate is over "who is right." Instead, the change advocate can in effect say, “This isn't about what you or I think is the right way to go. This is the direction coming to us from the outside.” It is important to note, however, that outside pressure didn’t create change advocates. They were there already. Had there been no change advocates to make this argument, “outside pressure” wouldn’t have helped in this regard. 


\section{II}

When procurement reform began, it was not supported by a majority of frontline procurement employees. However, by the time of the survey undertaken for the research (reflecting a period five years after the change effort began), there was both majority attitudinal support for reform and also significant behavior change that had occurred. In the survey of frontline procurement employees, the mean attitude towards procurement reform on a 100-point "feeling thermometer" (a technique commonly used in survey research), where 100 represented the strongest possible support for reform, 0 the strongest opposition, and 50 represented a neutral attitude, was 69.1. $70 \%$ of the sample gave a score greater than 50 , that is, expressed a positive view of reform. In the same survey, respondents were asked, "In terms of the way you do your job every day, how much impact has acquisition reform had?” The four response alternatives (so answers were coded on a l-4 scale) were: (l) "It has significantly changed the way I do my job," (2) "It has had some impact on the way I do my job,” (3) "It has had little impact on the way I do my job,” and (4) "It has had no impact on the way I do my job." The mean response was 1.81, that is, higher than "some impact."

Surely this growth in support could not have taken place unless people trying reform had mostly had positive experiences with it. My survey had five questions probing overall respondent experiences with reform once it got started. (Respondents were asked to agree or disagree with the following statements: “Acquisition reform has empowered me," "Acquisition reform has made my job easier," “Acquisition reform makes it easier to choose contractors who provide best value to the government," "Acquisition reform allows program people to get too close to contractors," and "I’ve seen acquisition reform deliver positive results in contract actions in which I've personally been involved.”) Respondents generally reported favorable experiences the mean response, on a five-point scale where "l” was “strongly agree," “3” was "mixed feelings,” and “5” was “strongly disagree,” was pro-reform for each question. Not surprisingly, these favorable experiences were an important reason support for reform spread.

However, the extent to which people reported positive experiences was generally rather modest. Most respondents agreed (mean value of 2.20, 68\% agreeing) they had personally experienced 
success stories as a result of reform. There was a similar level of agreement that reform had made it easier for the government to choose best-value contractors, which is good news from a taxpayer's perspective but did not correspond to an item that was particularly salient in the agenda of people on the front lines when the change effort began. On the two elements of reform tying in most closely with the discontents producing initial support for reform on the front lines, empowerment and reduction of job burdens, mean responses were surprisingly close to “ 3 ," which was a neutral response-2.80 for the empowerment question and 2.81 for the job easier. Only 43\% agreed, and a mere 9\% agreed "strongly,” that reform had empowered them and $41 \%$ that reform had made their jobs easier, $8 \%$ "strongly." $57 \%$ agreed with at least one of the two statements, only 28\% with both. (Overall mean values were positive even in situations where only a minority agreed with the statement because many respondents checked "mixed feelings.”) Yet 70\% of respondents reported an overall positive attitude towards reform. This suggests that attitudinal support for reform was doing better than positive experiences with it "warranted."

The gap, I believe, may be accounted for by operation of what social scientists call "positive feedback” mechanisms. Robert Jervis defines positive feedback as a process whereby “a change in one direction sets in motion reinforcing pressures that produce further change in the same direction.” In other words, once you get started in one direction, positive feedback mechanisms are those that encourage that direction to become entrenched. In a positive feedback view, the mere initiation of a change process and the mere passage of time a change process goes on generate forces increasing support for the change. Positive feedback mechanisms will have trouble continuing to act to increase support for change in the face of ongoing negative actual experiences. People won't continue to be fooled, or to fool themselves. But they allow support to increase beyond levels that would be implied by inherent features of people's experiences and allow support to increase in the face of neutral actual experience.

Positive feedback forces work in promoting development of support for an organizational change effort in two ways. First, they do so indirectly by increasing the extent to which a person has a positive experience with change, independent of features of the experience itself, but related to positive feedback-generating forces. The improved experience then works to improve support 
for the change. Second, they can do so by directly increasing attitudinal support for the change, independent of any impact on how positive people’s experiences were.

In my research, I found empirical evidence for no fewer than 19 positive feedback mechanisms working to increase support for procurement reform. Here I provide a few examples for illustration. Two positive-feedback mechanisms that have a positive impact on successful experience with the change are operation of the so-called "self-fulfilling prophecy" and of (what I call) “performance-promoting personality traits.”

Robert Merton, who first transferred the phrase from common speech into social science, defined a "self-fulfilling prophecy" as a prediction or expectation that evokes a behavior that makes the original prediction come true. How could this occur? Merton's basic argument was that beliefs, or expectations, may shape behavior. To take an example from outside the self-fulfilling prophecy, if I believe my car will explode if I turn on the ignition, I likely won't turn it on, so my belief shaped my behavior, regardless of whether in fact the ignition was wired with a bomb. If my expectation that I will succeed at something evokes more diligent behavior on behalf of success, then the existence of the expectation itself may help the expectation get realized. So people with a favorable inclination towards change would become more likely to gain positive experiences with the change, which in turn promotes the growth of attitudinal support.

Second, some personality traits make it easier for people to be successful at whatever they try. An example might be feeling driven to succeed at one's job. Presence of these characteristics thus provides positive feedback from the mere initiation of a change effort. People with these traits will work hard to succeed at whatever they are ask to do; if asked to try a new way of doing business, they will work hard to do it well; again, such successful experience promotes support for the change effort.

Other than inducing more positive experiences with the change, which in turn promotes support for it, positive feedback mechanisms may work directly to increase support for a change over 
time. Two such mechanisms are what psychologists call the "mere exposure effect" and "foot in the door."

By the “mere exposure effect” is meant the positive impact on a person's attitudes towards something of simple repeated exposure to that something. Albert Harrison illustrates its operation through the changed attitude of Parisians over time towards the Eiffel Tower. Now a beloved treasure regarded as symbolizing the city, the Tower initially was seen as hideous and evoked a storm of protest. However, "because of its tremendous height, the tower was ubiquitous and inescapable and hence was likely to be seen day after day. ... (P)erhaps attitudes towards the tower changed simply because it became a familiar part of the landscape.” In one experiment, subjects shown a photograph of themselves and a mirror-image photograph preferred the mirror-image photo, while for close friends of the subjects, the preference was reversed. In each case, subjects preferred the image they were most accustomed to seeing.

Before a change effort has begun, the mere exposure effect is one of the obstacles to successful change, because it increases support for established practices, independent of their benefits. However, once an organizational change effort has gone on for a long enough time, and people have tried the new behaviors often enough, the mere exposure film begins, so to speak, running backwards. At some point in a change process, some of the same phenomena that create support for the status quo and thus make change difficult to initiate start working to promote support for the change. Now, new behaviors that have been tried often enough begin to benefit from these mechanisms. The same factors that made it hard for change to gain a foothold in the first place, independent of the benefits of the status quo, begin to promote support for new ways of behaving, independent of their benefits.

Lee Ross and Richard Nisbett define "foot in the door" as a phenomenon whereby "inducing people to take initial small, seemingly inconsequential steps (puts them) along a path that ultimately will lead them to take much larger and more consequential actions.” The "foot in the door" mechanism was introduced into academic social psychology through a classic article of the same name, reporting on a natural-setting experiment in a neighborhood near Stanford University. A person randomly knocked on doors and asked people to sign an 
innocuous petition or place a small sign on their car window supporting safe driving. Not surprisingly, virtually all agreed to do so. Two weeks later, a different person went to the same houses and to an equal number of randomly selected houses that hadn't been approached with the original innocuous request, and asked people to place a large, crudely lettered, ugly "Drive Carefully” sign in their yard. $76 \%$ of those who had earlier undertaken the innocuous action in support of safe driving agreed, while only $17 \%$ of those who hadn't received the earlier visit did so. "Foot in the door" is a positive feedback mechanism because, once people have undertaken small steps towards changing traditional behaviors, it becomes easier to take larger ones, because they come to see themselves as the type of person who behaves this way.

\section{“Deepening” a "better value” agenda}

For many early supporters on the front lines, the change they were supporting was about streamlining the procurement process. For top leaders, it was about promoting the public good. To be sure, the reformers supported streamlining measures, from introduction of credit cards for small purchases through ways to streamline operation of the competitive process for larger buys. But streamlining efforts they favored fit into a larger strategy for obtaining better value (buying delays made mission attainment more difficult), and streamlining was only part of the reformers' agenda. The views people on the front lines had of what the change was "about" made it easier for change to get launched. But for the reformers, achieving change limited to "streamlining" might have been a Faustian bargain.

If they were fully to succeed, reformers needed to achieve what may be called a "deepening” of what people on the front lines supported in endorsing reform. By “deepening” I mean expansion over time of the extensiveness and character of new behaviors or beliefs someone supporting a change endorses. Partly, deepening is a matter of numbers: someone originally willing to endorse a small number of changes becomes willing to support a larger number. But often deepening involves transformation in the nature of changes. From only agreeing to undemanding changes, the person comes to accept more demanding ones. 
The job autonomy many sought was a personal desire, largely (though not entirely) to gain greater job satisfaction - though the evidence from the frontline survey was that people sought autonomy mostly for an opportunity to use their brains to engage in original thinking, rather than, as cynical observers (including academic principal-agent theory suggests) suspected, to work less hard (“shirk”), so these private desires might help accomplish public purposes. But job autonomy that was sought to give a chance engage in original thinking didn't exhaust the reformers' agenda. One might apply original thinking to doing an existing job better, such as by becoming a more intelligent negotiator, rather than by innovating. Furthermore, the evidence from the larger study was that a desire for reduction in job burdens, independent of the desire for autonomy, was a source of dissatisfaction with the traditional system. And there were important parts of the reformers' agenda that increased job demands rather than reducing them. One example was that the traditional system, fearful of giving government officials too much discretion and judgment, had blocked use of information about the past performance of bidders in making new contract awards, a situation that dramatically reduced the incentives of government contracts to perform well on their existing contracts. Making greater use of past performance in making new contract awards would, the reformers believed, generate better value for the government. But it would put new responsibilities on the shoulders of procurement employees.

The easier challenge for the reform leadership involved the majority of early supporters interested in job autonomy because they valued work requiring original thinking. For them, what was necessary -- for those not already supporting the better value agenda-would be, first, to direct their desire for work involving original thinking to embracing innovation and, second, to direct embrace of innovation to better value goals. Since they were already seeking work that required original thinking, this might not be so hard. Most drastically, deepening involved creating willingness among those initially sympathetic to reform, but seeing it mainly as a way to reduce personal job burdens, to support changes that would better serve the public but make their own jobs more difficult.

To discern the extent to which deepening had occurred, I examined responses measuring support of a better value agenda by survey respondents who had initially, based on answers to a number 
of questions, seen procurement reform as being mostly about reducing their personal job burdens. These data suggest top leaders enjoyed partial success. When, in the in-person interviews, respondents were asked to name what they saw as the main goals of procurement reform, relatively few mentioned goals related to better value. However, in forced-response questions, asking them to state whether they favored or opposed certain reform goals, most supported better-value goals.

Analysis of what factors were responsible for variation in support for better-value reform goals showed that support for these goals among those initially seeing reform as involving personal burden reduction largely resulted from two mechanisms. The first was categorization - the tendency to develop a mental category called "procurement reform” that was positively tinged and which got applied to anything associated with procurement reform, including better-value reforms. Those who believed reform had made their jobs easier were most likely to develop such a positive category. In this sense, deepening was how reformers got paid back, by those seeking personal benefits, for delivering what they had hoped to gain from reform. The second factor promoting deepening among these respondents was operation of a tendency (due to various positive feedback mechanisms) to like reform more simply because one had done it more. The increased liking for reform, simply based on more experience with it, got applied to the bettervalue agenda as well.

But there were important limits to the partial success top leaders enjoyed with achieving deepening. There was a large gap between active mention (in the in-person interviews) of better value as something important for reform and passive support (in the frontline survey) when specifically asked. Also, the two most important factors explaining deepening were the ones least involving conscious processes and hence explicit awareness, compared, say, with having been persuaded of the better-value agenda by leaders. In this sense, deepening was less a choice made by people and more something happening to people.

Ference Marton and Shirley Booth describe learning (or at least in one conception) as the ability to discern "aspects of the phenomenon other than those she had been capable of discerning before. ...When this occurs, the learner's awareness of the phenomenon has changed, and it 
appears different from before.” A good deal, though surely not all, of the deepening at the grassroots occurring with reform seems to have involved less awareness, and in this sense learning was less significant than it might have been. One would suspect also that less awareness of the change inside oneself that had occurred would in turn mean less translation of new attitudes into new behavior.

\section{$\underline{\text { Implications for Practitioners }}$}

Perhaps the most important result for practitioners from this research is that there may be more opportunities for successful frontline change than the dominant view about "barriers," “obstacles," and "resistance to change” suggests. To be sure, for what occurred in the case of procurement reform to be possible, there must be some baseline level of discontent with the organizational status quo on the front lines of an organization, some constituency for the kinds of organizational changes leaders seek to unleash. Although I only looked at dissatisfaction with the traditional system among frontline employees in the procurement system, one may expect that, similarly (though for different reasons, each peculiar to the peculiar facts of any given organizational situations) the organizational status quo in government agencies, when it is delivering sub-optimal results, is likely to be controversial, and there will be people on the front lines who share the agenda of change advocates at the top.

In the model of change initiation presented here, top leaders need not persuade, pressure, or scare people on the front lines, but only provide an opportunity for already-existing supporters to move. I would speculate that the most important reason top leaders do not more routinely provide such opportunity is that they never try in the first place. Senior political appointees do almost always launch initiatives of some sort when arriving in government, but these initiatives typically involve new policies or programs added on to existing ones, rather than efforts to change the existing behavior of the organization, particularly at the working level. This reflects the fact that political appointees are typically attracted to government service far more by the opportunity to influence policy than to manage the organization's production. 
A second important reason is that top leaders may attempt change, but not seek frontline allies. The view that "employees resist change" is widely held. Top leaders who hold this view may seek to get change started behind employees’ backs, so it gets established before people on the front lines can stop it. The view of many top leaders that they are unlikely to have frontline allies in the change process can thus become a self-fulfilling prophecy - it is a belief about the people on the front lines that generates behavior that makes the belief come true. For this reason, getting leaders to realize that there may be frontline support for change is perhaps the most important practical contribution of this research finding. It may itself increase the chances of successful change initiation, if it gets leaders to believe that providing an opportunity to frontline allies is a way to initiate change.

A positive feedback approach to thinking about the spread of support for change has several implications. The first is to provide another reason for a "bias for action," first enunciated as a principle of good management in In Search of Excellence over twenty years ago. Positive feedback effects constitute a reason for a "bias for action” in organizational change efforts: if you can get a change effort started, there will be forces encouraging the process to spread, just because it has gotten started.

We should notice how the positive feedback perspective differs from the prescription about achieving "early wins" that is extremely common in organizational change literature - the idea that early successes promote spread of support for a change effort. This argument requires successful early experience. By contrast, although of course change will not be able to continue to spread in the face of ongoing failed results, positive feedback does not require "wins," and certainly not unambiguous ones, for support for change to spread. Early wins are not required. Early action is enough.

Second, the positive feedback approach argues that the longer a change effort continues the more support it is likely to garner. What leaders provide is persistence. One reason such persistence is not often seen in change efforts in government is that senior political appointees generally have short tenures. By contrast, I stayed four years and was replaced by a successor sharing the same approach. Colleen Preston, my Defense Department colleague, stayed three years and, similarly, 
was replaced by a like-minded successor. Another difference between procurement reform and many other change efforts is that, as top leaders of the effort, we had few other job responsibilities. Other top leaders have operating organizations to run. This makes it very difficult for them to devote large blocks of time over sustained periods to organizational change. The odds are high something else will “come up” to preoccupy the time and attention of a leader in charge of running an organization with ongoing operating responsibilities other than a change effort the leader might have originally launched. By contrast, Preston and I were able to display a persistence it would be hard for many others to show. Also, leaders, like other people, have a tendency to get bored with what they are doing, and to seek out the exhilaration of something new - before what they have completed what was earlier started. Top-leader persistence is thus very rare in change efforts.

"Path dependence” is the idea that, as Robert Jervis puts it, because of positive feedback mechanisms "small and often accidental differences between two actors at an early stage can lead to enormous divergences later on.” Students of path dependence often find “Cleopatra's noses" - instances in which the flow of events is strongly influenced by some unpredictable aspect of the situation, such as the size of Cleopatra's nose which, had it been different, would have made her less attractive to Marc Antony, through a complex path, and changed the course of history. The idea of path dependence suggests greater possibilities for success in change efforts than is often suspected. As Robert Jervis puts it, "Looking back after the pattern is established, we may overestimate the degree of determinism involved.” A leader contemplating setting a change effort in motion might be disheartened observing the large difference between where the organization is now and where an organization that had succeeded at changing itself is - and assume that these big current differences might reflect big differences going in that would make it hopeless even to consider a change effort. A positive feedback perspective should encourage practitioners not to assume there are unbreachable differences between their organizations and those that have successfully changed. They suggest a final reason for leaders to be more optimistic about their chances of success - if they try and are persistent - than dominant views of the possibilities of successful organizational change in government would lead them to believe. 